\title{
Gas-particle partitioning of atmospheric aerosols: interplay of physical state, non-ideal mixing and morphology
}

\begin{abstract}
Manabu Shiraiwa, $\nmid \ddagger^{a}$ Andreas Zuend, $₫ \S^{a}$ Allan K. Bertram ${ }^{b}$ and John H. Seinfeld ${ }^{* a}$
Atmospheric aerosols, comprising organic compounds and inorganic salts, play a key role in air quality and climate. Mounting evidence exists that these particles frequently exhibit phase separation into predominantly organic and aqueous electrolyte-rich phases. As well, the presence of amorphous semi-solid or glassy particle phases has been established. Using the canonical system of ammonium sulfate mixed with organics from the ozone oxidation of $\alpha$-pinene, we illustrate theoretically the interplay of physical state, non-ideality, and particle morphology affecting aerosol mass concentration and the characteristic timescale of gas-particle mass transfer. Phase separation can significantly affect overall particle mass and chemical composition. Semi-solid or glassy phases can kinetically inhibit the partitioning of semivolatile components and hygroscopic growth, in contrast to the traditional assumption that organic compounds exist in quasi-instantaneous gas-particle equilibrium. These effects have significant implications for the interpretation of laboratory data and the development of improved

atmospheric air quality and climate models.
\end{abstract}

Received 14th April 2013,

Accepted 29th May 2013

DOI: $10.1039 / \mathrm{c} 3 \mathrm{cp} 51595 \mathrm{~h}$

www.rsc.org/pccp

\section{Introduction}

Tropospheric aerosols in the submicrometer size range comprise a mixture of inorganic salts, organic compounds, and water. These suspended microscopic particles play an important role in air quality, climate and public health. ${ }^{1}$ Atmospheric aerosols exert, on the whole, a cooling effect on climate, partially offsetting the warming attributable to the growing burden of greenhouse gases. ${ }^{2}$ The magnitude of the aerosol cooling effect constitutes the largest uncertainty in determining the Earth's climate sensitivity to a doubling of greenhouse gas levels. ${ }^{2}$ The dominant fraction of the organic portion of atmospheric particles is secondary organic aerosol (SOA), formed from the oxidation of volatile organic compounds to yield low-volatility products that partition into the aerosol phase; organic compounds typically contribute from $30 \%$ to $80 \%$ of

\footnotetext{
${ }^{a}$ Division of Chemistry and Chemical Engineering, California Institute of Technology, Pasadena, CA 91125, USA. E-mail: seinfeld@caltech.edu

${ }^{b}$ Department of Chemistry, University of British Columbia, Vancouver, BC, V6T 1Z1, Canada

† Present address: Multiphase Chemistry Department, Max Planck Institute for Chemistry, 55128 Mainz, Germany.

$\ddagger$ These authors contributed equally to this work.

$\S$ Present address: Institute for Atmospheric and Climate Science, ETH Zurich, 8092 Zurich, Switzerland.
}

the aerosol mass. ${ }^{3,4}$ One of the grand challenges of atmospheric chemistry is to understand how chemistry and gas-particle partitioning of inorganic and organic species influence mass concentrations (i.e., particulate matter mass per unit volume of air), chemical composition, and size distribution of atmospheric aerosols.

Thermodynamic models of organic-inorganic-water mixtures characteristic of atmospheric aerosols predict complex, nonideal behavior that includes liquid-liquid or liquid-solid phase separation. ${ }^{5,6}$ The existence of multiple phases and morphologies in organic-inorganic particles, as predicted by such models, has been demonstrated in the laboratory ${ }^{7-11}$ and field. ${ }^{12,13}$ Recent work has also shown that the physical state of the organic-rich phase in atmospheric organic-inorganic particles can be liquid (low dynamic viscosity $\eta ; \eta<10^{2} \mathrm{~Pa} \mathrm{~s}$ ), semi-solid (highly viscous 'liquid'; $10^{2} \leq \eta \leq 10^{12}$ Pa s), or solid (crystalline or glass; $\eta>10^{12} \mathrm{~Pa} \mathrm{~s}$ ), depending on the composition and ambient conditions. ${ }^{14-17}$ Aqueous solutions of a number of organic substances tend to form semi-solid or amorphous solid (glassy), rather than crystalline, phases as humidity decreases. ${ }^{15}$ Ambient particles in boreal forests as well as laboratory-generated particles, consisting predominantly of SOA, have been observed to bounce off the smooth hard surface of an inertial impactor, implying a non-liquid state. ${ }^{18,19}$ Upon dilution or heating, SOA particles can evaporate 
unexpectedly slowly, as a result of retarded mass transfer from the particle bulk to the surface, characteristic of semi-solid behavior. $^{20,21}$ All these observations are consistent with the presence of low-volatility and higher molecular weight organic compounds that are known to form in organic aerosols $;^{22}$ such compounds tend to have high glass transition temperatures and may lead to semi-solid or glassy phases. ${ }^{17}$ Traditionally, gas-particle equilibrium partitioning of organic substances is assumed to be established instantaneously ${ }^{4,23,24}$ ("instantaneously" being interpreted as rapid when compared to the timescales of the other major atmospheric processes associated with SOA formation); this assumption is in question if particles or certain phases therein are semi-solid or glassy. ${ }^{21,25,26}$

Atmospheric large-scale models serve as the basis for predicting the concentration and composition of ambient aerosols associated with air quality and climate. ${ }^{23}$ Current large-scale models represent aerosol physicochemical processes by highly simplified schemes, inherently neglecting the actual nature and compositional complexity of aerosol particles. Many models substantially under-predict observed aerosol total mass. ${ }^{4}$ While under-accounting for the actual sources of organic particulate matter is likely important, an unresolved issue is how aerosol physical state and morphology influence atmospheric aerosol growth and evolution. For example, to what extent does the existence of phase separation and particle-phase non-ideality influence gasparticle partitioning? And, what is the effect of slow mass transfer on the establishment of gas-particle equilibrium? Here, these questions are addressed with state-of-the-art thermodynamic and kinetic models capable of simulating the complex phenomena involved in atmospheric gas-particle partitioning. The mixture of ammonium sulfate and organics from the ozone oxidation of $\alpha$-pinene serves as a canonical system, for which aerosol composition is reasonably well established. ${ }^{4,23}$ Using this system, we illustrate key aspects of the effects of physical state, non-ideal mixing, and morphology on gas-particle partitioning.

\section{Gas-particle partitioning, non-ideal mixing, and particle morphology}

The formation of multiple phases and different particle morphologies in organic-inorganic aerosols reflects the complex interplay of composition, partitioning, and non-ideal condensed phase thermodynamics. The effects of aerosol water content on particle composition, morphology, viscosity, and optical properties are especially important. The equilibrium water content of a particle is controlled by its composition and varies in correspondence to changes in the relative humidity $(\mathrm{RH})$ of the surrounding air. Water is an excellent solvent for inorganic electrolyte species such as ammonium sulfate, particularly under dilute conditions. Water is also a solvent for highly oxygenated, hydrophilic organic compounds. However, mixtures of both hydrophilic and hydrophobic organic compounds, water and dissolved electrolytes tend to exhibit substantial non-ideal thermodynamic behavior, a consequence of which is liquid-liquid phase separation and/or formation of solid phases. ${ }^{5,6,27,28}$

Fig. $1 \mathrm{a}$ and $\mathrm{b}$ show the effect of $\mathrm{RH}$ on the mixture of water, ammonium sulfate, and organics from the ozone
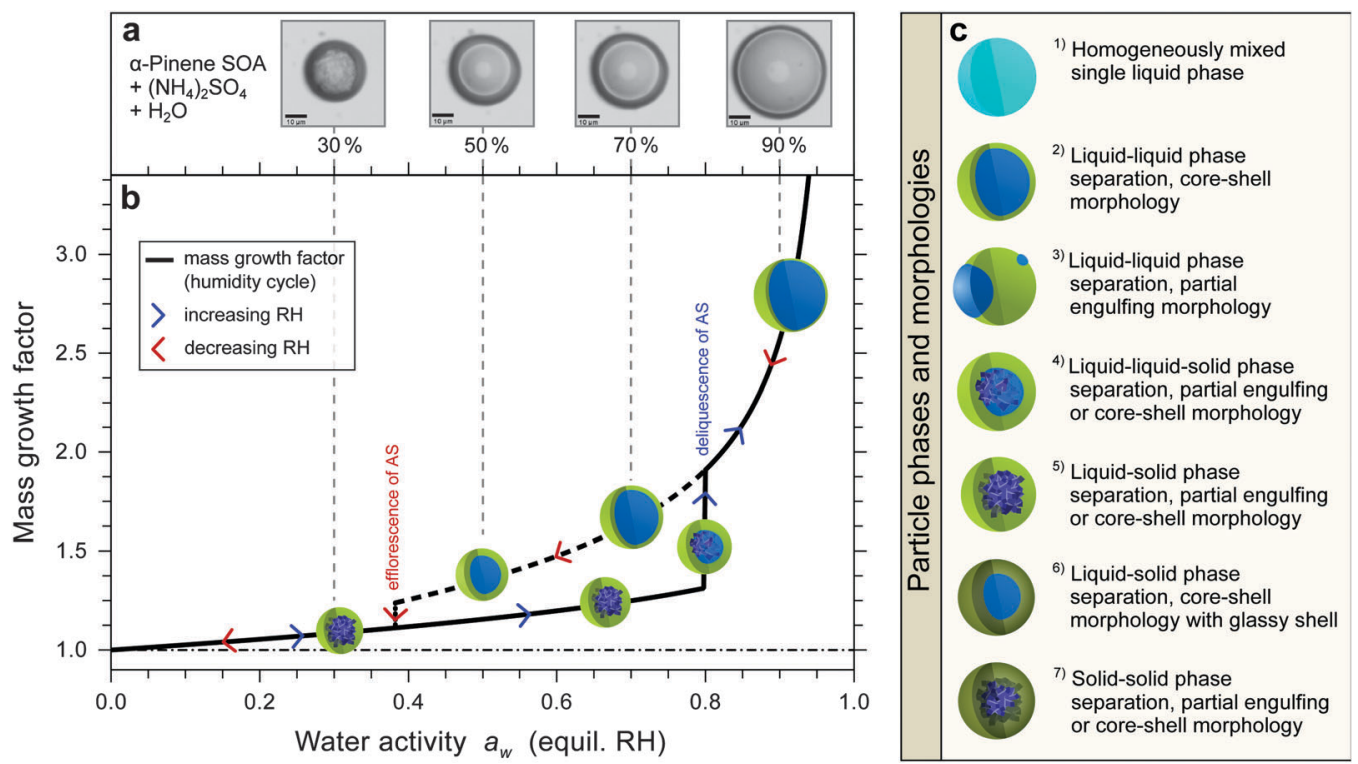

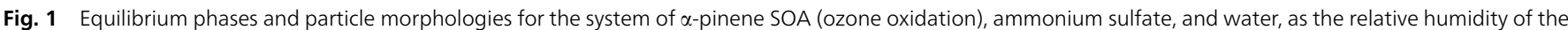

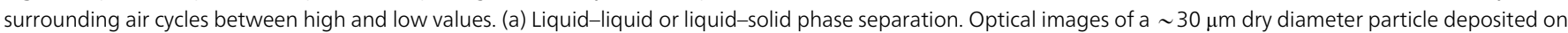

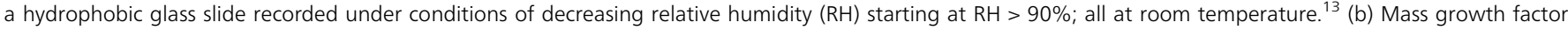

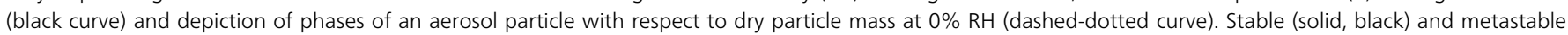

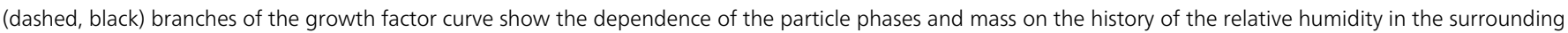

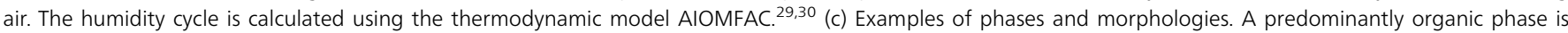

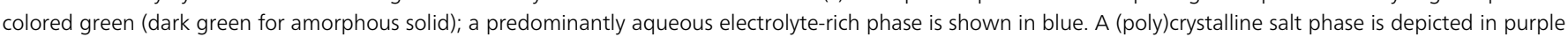

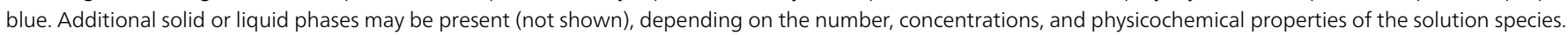


oxidation of $\alpha$-pinene. The mass growth factor of such an aerosol particle (the total change in particle mass relative to the dry state at $0 \% \mathrm{RH}$ ) as a function of mole fraction-based water activity (i.e. equilibrium RH) is shown in Fig. 1b, predicted using a thermodynamic equilibrium model based on AIOMFAC (Aerosol Inorganic-Organic Mixtures Functional groups Activity Coefficients) (details given in Appendix A). ${ }^{29,30}$ The mass change with increasing $\mathrm{RH}$ results from the uptake of water accompanied by a change in the gas-particle partitioning of the organic components. The amount of water uptake depends on whether ammonium sulfate is present predominantly in solid form or whether the electrolyte is completely dissolved in an aqueous solution; the latter is the case above the deliquescence point (solubility limit) of ammonium sulfate in this system, here at $\mathrm{RH} \sim 80 \%$. The organic/ammonium sulfate dry mass ratio is $\sim 1.5$ in this calculation, and the total organic mass ranges from $\sim 1.7 \mu \mathrm{g} \mathrm{m}^{-3}$ to $\sim 2.4 \mu \mathrm{g} \mathrm{m} \mathrm{m}^{-3}$ for $\sim 2.45 \mathrm{ppb}_{\mathrm{v}}$ of $\alpha$-pinene reacted.

Thermodynamic equilibrium specifies that this system exhibits liquid-liquid phase separation up to high RH. Visualizations of supermicron-sized droplets generated in the $\alpha$-pinene SOA system are in good agreement with this prediction (Fig. 1a). ${ }^{13}$ Studies with submicron-sized particles consisting of ammonium sulfate and organics from the ozonolysis of $\alpha$-pinene are also consistent with these thermodynamic calculations. ${ }^{31}$ Phase-separated microscopic organic-inorganic solution droplets can adopt either a partial engulfing morphology in which the internal aqueous electrolyte-rich phase maintains contact with the gas-phase or a core-shell morphology with the organic-rich phase as the shell (sometimes called "coating", especially in case of a solid core $)^{9,10,13}$ as depicted in Fig. 1c. The extent to which a phase-separated aerosol adopts a partial engulfing or core-shell morphology depends on the relative differences of the volumes and interfacial tensions (interfacial energies) between all phases involved. ${ }^{7,9}$ The interfacial tensions, in turn, depend on the compositions of the phases; therefore, the particle morphology changes in response to substantial variations in $\mathrm{RH}^{9,10}$ In the case of core-shell structure with a semi-solid or glassy organic shell phase, mass transfer of water and organic compounds can be kinetically limited $;^{15,25}$ implications of this situation are discussed below.

\section{Equilibrium phase compositions}

Fig. 2 shows computed RH-dependent gas and particle compositions at gas-particle equilibrium for the system of Fig. 1, for $\mathrm{RH}$ decreasing from $99 \%$ to $30 \%$ at $T=298 \mathrm{~K}$. Component acronyms listed in Fig. 2a are given in Table 1. The water-free
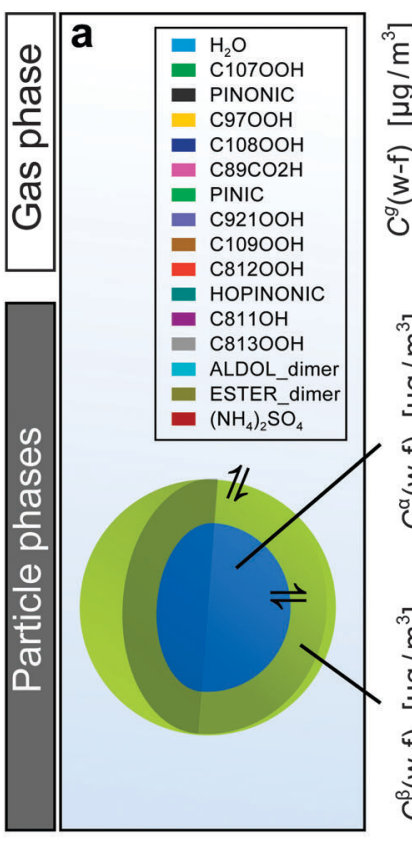
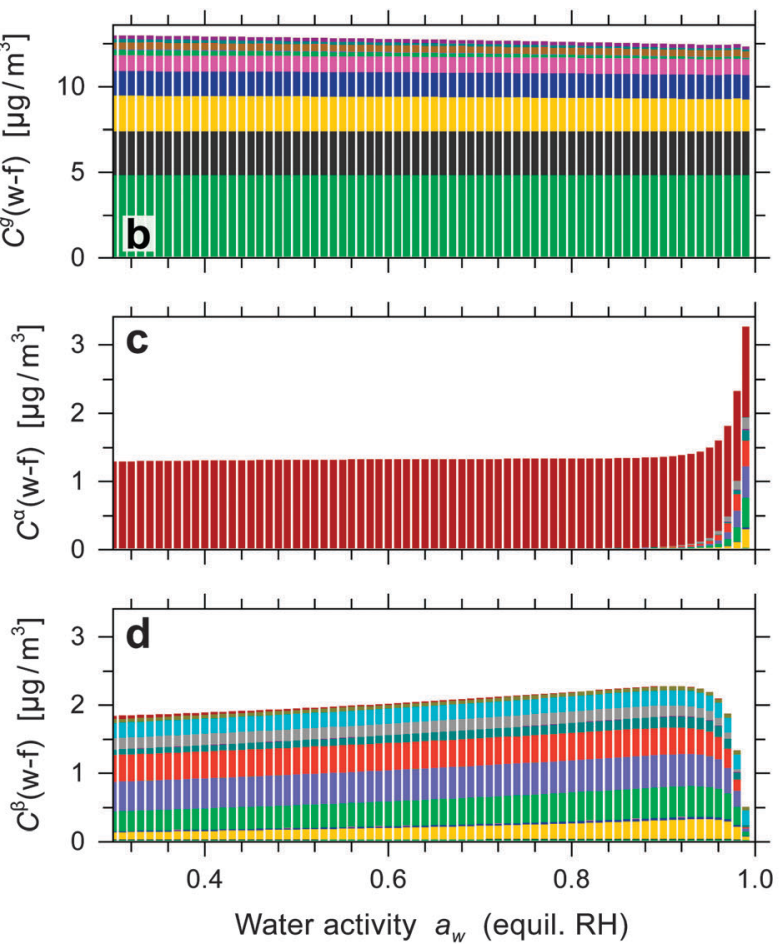
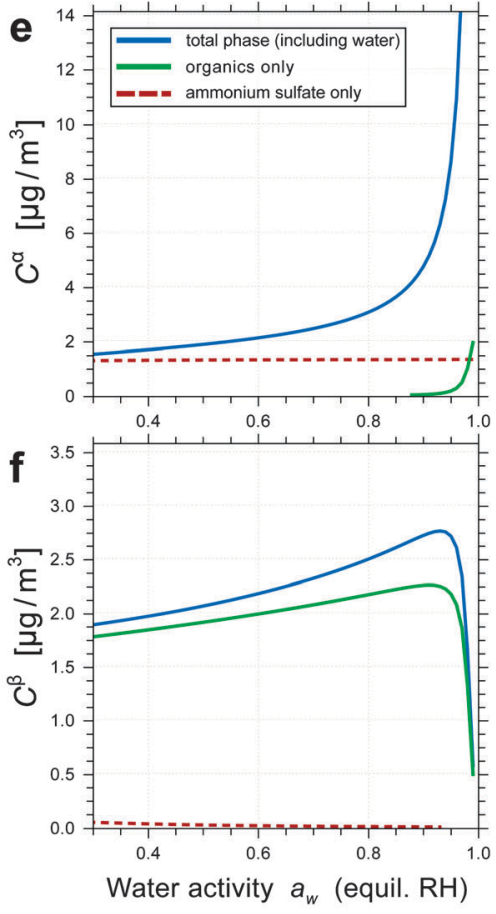

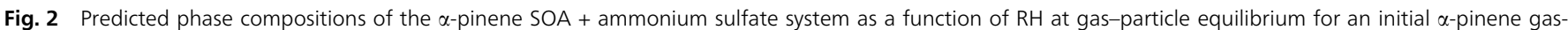

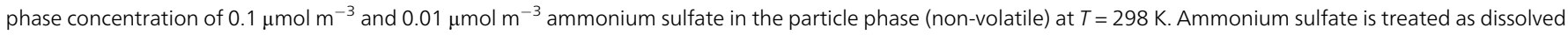

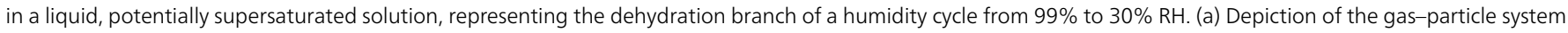

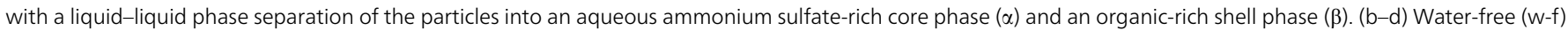

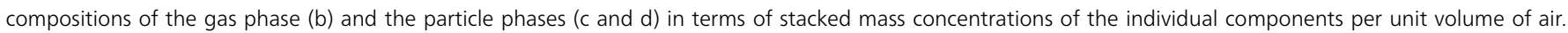

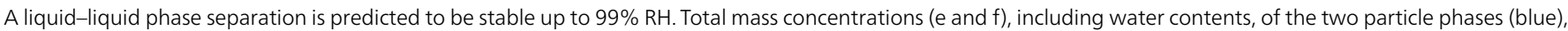

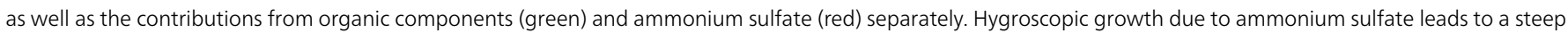
increase in mass of phase $\alpha$ at $\mathrm{RH}>90 \%$. 
Table 1 Set of secondary organic aerosol products from the oxidation of $\alpha$-pinene by ozone used in the model system. Compounds and stoichiometric molar yields are derived from the Master Chemical Mechanism (MCM v3.1) chamber experiment simulation reported by Shilling et al. ${ }^{78}$ for the reaction of $0.9 \mathrm{ppb}_{v} \alpha$-pinene. Simulation conditions: $T=298.15 \mathrm{~K}, 40 \% \mathrm{RH}, 300 \mathrm{ppb}_{\mathrm{v}}$ Ozone, 0.94 ppm $_{\mathrm{v}}$ 1-butanol, dry ammonium sulfate seed particles, and $3.4 \mathrm{~h}$ residence time. Additional products not considered here and further details are given in Zuend and Seinfeld ${ }^{6}$

\begin{tabular}{|c|c|c|c|}
\hline Structure & $\begin{array}{l}\text { Molar mass } \\
{\left[\mathrm{g} \mathrm{mol}^{-1}\right]}\end{array}$ & $\begin{array}{l}p^{\mathrm{o}, \mathrm{L}}(298.15 \mathrm{~K})^{b} \\
{[\mathrm{~Pa}]}\end{array}$ & $\begin{array}{l}\text { Molar } \\
\text { yield }^{c}\end{array}$ \\
\hline $\mathrm{C} 107 \mathrm{OOH}$ & 200.231 & $7.8328 \times 10^{-3}$ & 0.23849 \\
\hline PINONIC & 184.232 & $1.5345 \times 10^{-2}$ & 0.14013 \\
\hline $\mathrm{C} 97 \mathrm{OOH}$ & 188.221 & $5.4035 \times 10^{-4}$ & 0.11496 \\
\hline C1080OH & 216.231 & $1.8447 \times 10^{-3}$ & 0.06707 \\
\hline $\mathrm{C} 89 \mathrm{CO} 2 \mathrm{H}$ & 170.206 & $4.6884 \times 10^{-2}$ & 0.05400 \\
\hline PINIC & 186.205 & $4.7358 \times 10^{-5}$ & 0.03182 \\
\hline $\mathrm{C} 921 \mathrm{OOH}$ & 204.220 & $4.4946 \times 10^{-6}$ & 0.02443 \\
\hline C1090OH & 200.231 & $1.5128 \times 10^{-2}$ & 0.01928 \\
\hline $\mathrm{C} 812 \mathrm{OOH}$ & 190.194 & $1.2132 \times 10^{-6}$ & 0.02132 \\
\hline HOPINONIC & 200.232 & $7.6498 \times 10^{-5}$ & 0.01350 \\
\hline $\mathrm{C} 811 \mathrm{OH}$ & 158.094 & $3.1129 \times 10^{-3}$ & 0.01371 \\
\hline $\mathrm{C} 813 \mathrm{OOH}$ & 206.193 & $2.0391 \times 10^{-7}$ & 0.00825 \\
\hline ALDOL_dimer ${ }^{d}$ & 368.421 & $1.1579 \times 10^{-11}$ & 0.00600 \\
\hline ESTER_dimer ${ }^{d}$ & 368.421 & $2.5279 \times 10^{-11}$ & 0.00150 \\
\hline \multicolumn{4}{|c|}{$\begin{array}{l}{ }^{a} \text { Names as assigned by the MCM; exceptions: the two dimer com- } \\
\text { pounds. }{ }^{b} \text { Pure component liquid state vapor pressure at temperature } \\
T=298.15 \mathrm{~K} \text {, estimated using the EVAPORATION model. }{ }^{c}{ }^{c} \text { Stoichio- } \\
\text { metric molar yields of the products with respect to moles of parent } \\
\text { hydrocarbon ( } \alpha \text {-pinene) reacted. }{ }^{d} \text { Two dimer compounds as surrogates } \\
\text { for several dimers assumed to exist in the condensed phase. The } \\
\text { ALDOL_dimer is formed by aldol condensation of C108OOH } \\
\text { C89CO2H; the ESTER_dimer is formed by ester formation from } \\
\text { HOPINONIC + PINIC. A stoichiometric yield of } 10 \% \text { with respect to } \\
\text { the maximum possible amounts (from the involved monomers) are } \\
\text { here assumed for both dimers. }\end{array}$} \\
\hline
\end{tabular}

composition diagrams of the two particle phases show a clear distinction between an aqueous electrolyte-rich phase $\alpha$ (Fig. 2c) and a predominantly organic phase $\beta$ (Fig. 2d). The water contents associated with the particle phases are shown in Fig. 2e and f. For $\mathrm{RH}<90 \%$, liquid-liquid phase separation between organic components and ammonium sulfate is virtually complete, with water being the only component present in both phases at a significant mass fraction. Above $\sim 90 \%$ $\mathrm{RH}$, the partitioning of moderately hydrophilic organic compounds to phase $\alpha$ becomes significant as the water content in phase $\alpha$ increases substantially.

While the mole-fraction based activity coefficients of the organic components in the organic-rich phase $\beta$ are predicted to vary by less than a factor of two over the $\mathrm{RH}$ range of $30 \%-90 \%$, the corresponding activity coefficients in the electrolyte-rich phase vary over more than eight orders of magnitude (Fig. 5). This enormous change in activity coefficients drives the phase separation. Assuming that the particle consists of a single, homogenously mixed phase leads to a substantially different gas-particle distribution of organic components. Ignoring liquid-liquid phase equilibrium in predicting thermodynamic gas-particle partitioning, even when accounting for the effects of non-ideal mixing (in a single liquid phase), can lead to both significant underprediction of aerosol mass and incorrect particle composition, particularly at moderate and lower RH levels. ${ }^{6}$ Ignoring non-ideality entirely by assuming an ideal, single-phase organic-inorganic aerosol mixture can lead to substantial overprediction of SOA partitioning to the particles at higher $\mathrm{RH}$, since in this case the miscibility of typical SOA components with water and dissolved electrolytes is overestimated. ${ }^{6}$ Such effects are especially important for systems containing SOA of moderate to lower hygroscopicity (a first-order proxy of which is an atomic oxygen-to-carbon $(\mathrm{O}: \mathrm{C})$ ratio below $\sim 0.8) .{ }^{8,11}$ Since SOA of moderate to lower hygroscopicity forms frequently in the atmosphere, ${ }^{32-34}$ liquidliquid phase separation needs to be accounted for in atmospheric models of detailed gas-particle processes. Parameterizations aiming at computational efficiency, while considering the RH-dependency of liquid-liquid and liquid-solid phase transitions, are needed for the development of next-generation air quality and chemistry-climate models. ${ }^{6,8,11}$

\section{Equilibration timescale of SOA partitioning}

The characteristic timescale to reach equilibrium partitioning can be estimated using the kinetic multi-layer model of gas-particle interactions (KM-GAP) ${ }^{35}$ coupled with AIOMFAC. KM-GAP represents the particle phase with multiple compartments and layers, including a surface sorption layer and a number of bulk layers and treats gas-phase diffusion, reversible adsorption, and bulk diffusion explicitly (see Fig. 3a and Appendix B). Here we assume a particle of a core-shell morphology, the shell phase of which is predominantly organic and the core phase is an aqueous electrolyte-rich solution (Fig. 3a). To perturb the system away from its equilibrium state shown in Fig. 2, the organic gas-phase concentrations are instantaneously changed by a factor of 5 to either smaller or larger values, leading to particle evaporation or growth, respectively. $\mathrm{RH}$ is held constant in this set of simulations and monodisperse particles are assumed. The equilibration timescale, $\tau_{\text {eq }}$, 

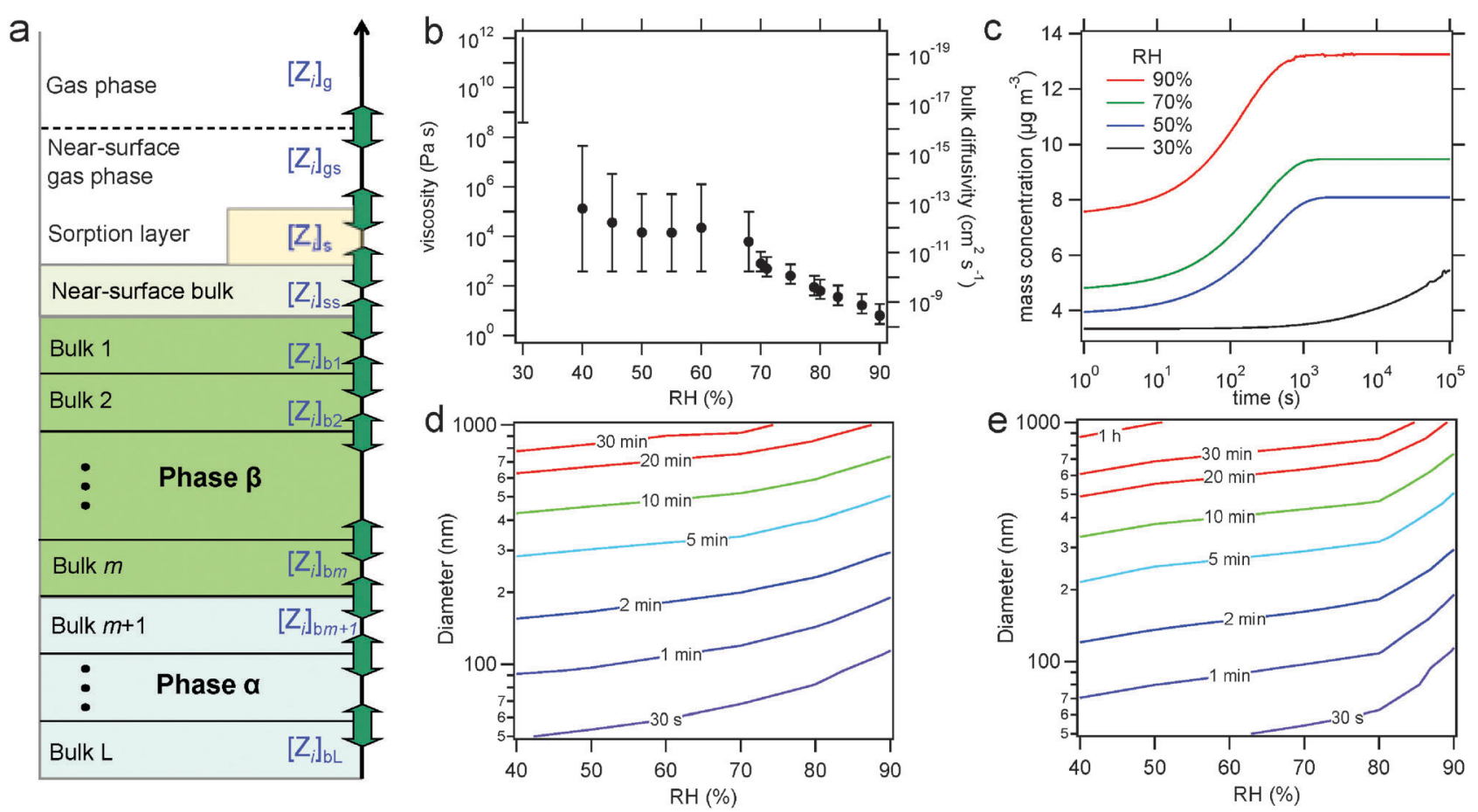

Fig. 3 Kinetic modeling of gas-particle partitioning for the phase-separated $\alpha$-pinene SOA core-shell aerosol system. (a) Schematic of the KM-GAP model compartments and layers with corresponding bulk concentrations for a particle consisting of separate phases $\alpha$ (aqueous electrolyte-rich phase) and $\beta$ (organic-rich phase). Green arrows denote mass transport fluxes. (b) Measured viscosity (left axis) of extracted $\alpha$-pinene SOA. ${ }^{36}$ Bulk diffusion coefficient (right axis) is obtained through the Stokes-Einstein equation. (c) Evolution of total mass concentration of initially $300 \mathrm{~nm}$ diameter particles at different RH under net growth conditions. Equilibration timescale for particle growth (d) and evaporation (e) with respect to RH and particle diameter, calculated using bulk diffusivity shown in the panel (b). Below $40 \% \mathrm{RH} \tau_{\text {eq }}$ is estimated to be on the order of hours to days depending on the assumed bulk diffusivity of $<10^{-17} \mathrm{~cm}^{2} \mathrm{~s}^{-1}$.

is defined as the $e$-folding time associated with the approach of the total particle mass concentration to equilibrium.

Fig. $3 \mathrm{~b}$ shows the measured viscosity of extracted $\alpha$-pinene SOA using bead-mobility and poke-flow techniques, which suggests that the physical state of the SOA-rich phase is liquid for $\mathrm{RH} \geq 80 \%$, semi-solid for $30 \%<\mathrm{RH}<80 \%$, and semisolid or amorphous solid for RH $\leq 30 \% \cdot{ }^{36}$ At dry conditions the SOA viscosity is estimated to be $>10^{8} \mathrm{~Pa} \mathrm{~s}$ based on evaporation experiments. ${ }^{37}$ Viscosity of materials can be converted to bulk diffusivities using the Stokes-Einstein equation, which is a suitable approach for organic molecules in a liquid or semi-solid phase. ${ }^{16,17}$ The bulk diffusivities are used as input parameters for the KM-GAP simulations. The particle mass concentration attains a new equilibrium more slowly at lower RH (Fig. 3c), mainly owing to lower bulk diffusivity of organic compounds in the (semi-)solid matrix at lower RH. The core phase, which contains essentially only water and dissolved ammonium sulfate (at RH $<90 \%$ ), remains unchanged, maintaining a water activity in equilibrium with the gas-phase RH, while the volume of the shell phase increases owing to organic condensation (Fig. 6). For particle growth and evaporation, $\tau_{\mathrm{eq}}$ is on the order of minutes and becomes longer as RH decreases and as particle diameter increases (Fig. 3d and e). Below $40 \%$ $\mathrm{RH} \tau_{\text {eq }}$ is estimated to be on the order of hours to days depending on the assumed bulk diffusivity of $<10^{-17} \mathrm{~cm}^{2} \mathrm{~s}^{-1}$. Note that the values of $\tau_{\text {eq }}$ are subject to uncertainty of at least a factor of 10 due to large uncertainty in the viscosity measurements at RH $\leq 70 \%$. Nevertheless, the predicted $\tau_{\text {eq }}$ is qualitatively consistent with observations of slow evaporation of ambient and laboratory-generated SOA at low $\mathrm{RH}^{21,38}$ An assumption of quasi-instantaneous equilibrium gas-particle partitioning may hold at high $\mathrm{RH}$, but this assumption may lead to overestimation of organic particle mass concentrations and, consequently, underestimation of gas-phase concentrations at low RH when equilibration occurs slowly. ${ }^{25}$ Retarded equilibration also affects measurements of aerosol volatility and vaporization enthalpies. ${ }^{20,39}$

\section{Hygroscopic growth timescale of SOA}

Hygroscopicity is an important property of aerosols with implications for climate, as it is directly related to the ability of aerosol particles to serve as cloud condensation nuclei (CCN). Particle size, hence the optical properties of particles, is also dependent on hygroscopicity. The dynamic nature of the hygroscopic response of a particle to a change in $\mathrm{RH}$ depends on the facility with which $\mathrm{H}_{2} \mathrm{O}$ molecules diffuse in the particle bulk. The bulk diffusion coefficient of water $\left(D_{\mathrm{H}_{2}} \mathrm{O}\right)$ in the $\alpha$-pinene SOA-rich phase at $298 \mathrm{~K}\left(D_{\mathrm{H}_{2} \mathrm{O}}\right)$ is estimated (Fig. 4a) from percolation theory ${ }^{16}$ based on the hygroscopic growth data presented in Fig. 2 and $D_{\mathrm{H}_{2} \mathrm{O}}$ in aqueous sucrose glasses ${ }^{40}$ which is thought to have similar viscosity as SOA (see Appendix C for additional details). 

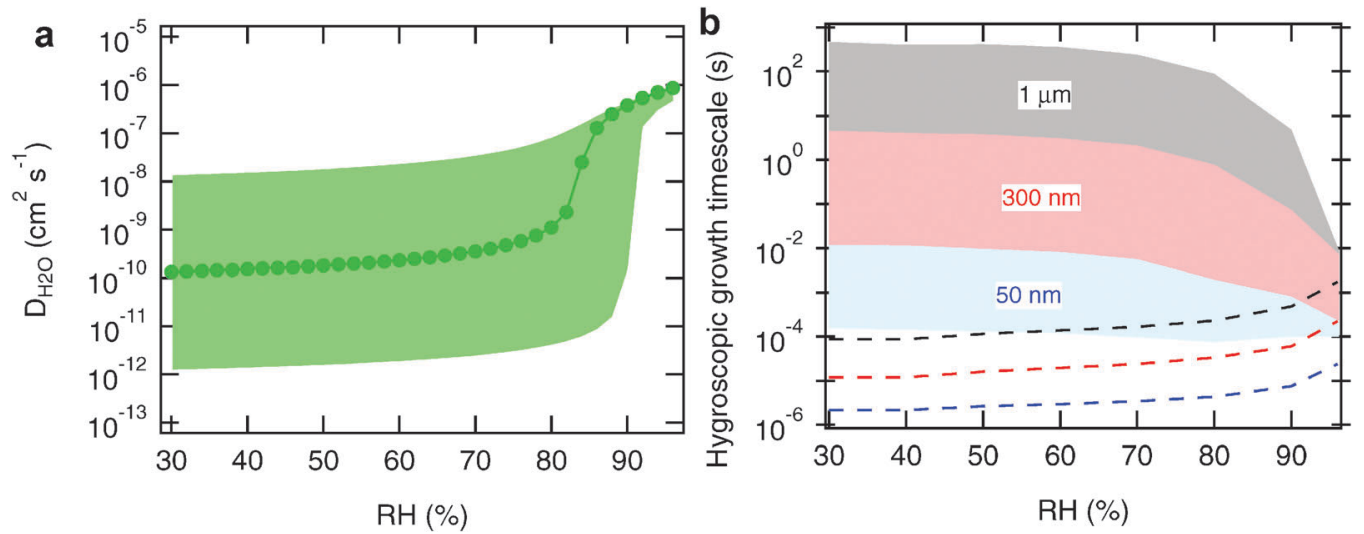

Fig. 4 Water uptake mass transfer kinetics at room temperature. (a) Bulk diffusion coefficient of water in the organic-rich phase as a function of RH, estimated by percolation theory. The shaded green area represents estimated uncertainty. (b) Equilibration timescale of hygroscopic growth of $\alpha$-pinene SOA as a function of RH when $\mathrm{RH}$ is increased by $2 \%$. Particle diameters of $50 \mathrm{~nm}$ (blue), $300 \mathrm{~nm}$ (red), and $1 \mu \mathrm{m}$ (gray) are assumed. Two core-shell morphologies are considered: $(\alpha-\beta)$ the electrolyte-rich phase as the shell with the organic-rich phase as the core (dashed lines); and $(\beta-\alpha)$ the organic-rich phase as the shell with the electrolyte-rich phase as the core (shaded areas)

Note that for the estimation of diffusivities of small molecules (e.g. $\mathrm{H}_{2} \mathrm{O}$ ) diffusing through a (semi-)solid matrix, the StokesEinstein equation is not applicable. ${ }^{16,17}$ The large estimated uncertainty reflects the lack of direct measurements of $D_{\mathrm{H}_{2} \mathrm{O}}$ in SOA (see Appendix C). $D_{\mathrm{H}_{2} \mathrm{O}}$ in semi-solid SOA is predicted to be $\sim 10^{-10} \mathrm{~cm}^{2} \mathrm{~s}^{-1}$ at $\mathrm{RH}<80 \%$, jumping to $\sim 10^{-7} \mathrm{~cm}^{2} \mathrm{~s}^{-1}$ at $\mathrm{RH}$ of $\sim 80 \%$, the percolation threshold (establishment of long-range connectivity) for water diffusion through the organic matrix.

The characteristic timescale of hygroscopic growth of the particle, $\tau_{\text {hg }}$, is simulated with KM-GAP using the estimated $D_{\mathrm{H}_{2} \mathrm{O}}$ (RH-dependent). $\tau_{\mathrm{hg}}$ is defined as the $e$-folding time associated with the approach of the total particle mass concentration toward thermodynamic equilibrium. The initial chemical composition of the $\alpha$-pinene SOA + ammonium sulfate system, including equilibrium water content in the two phases, is given in Fig. 2. We increase RH instantaneously by $2 \%$, a perturbation sufficiently small that bulk diffusivity and activity coefficients are essentially unchanged during the hygroscopic growth response. Two contrasting core-shell morphologies are considered in these simulations: $(\alpha-\beta)$ the electrolyte-rich phase as the shell with the organic-rich phase as the core and $(\beta-\alpha)$ the organic-rich phase as the shell with the electrolyte-rich phase as the core. Initial particle diameters, of $50 \mathrm{~nm}, 300 \mathrm{~nm}$, and $1 \mu \mathrm{m}$, are assumed. The bulk diffusivity of water in the electrolyte-rich "inorganic" phase is taken to be $10^{-5} \mathrm{~cm}^{2} \mathrm{~s}^{-1}$, a value typical for water in low-viscosity liquids. ${ }^{16,17}$ For the $(\alpha-\beta)$ structure the surface accommodation coefficient of water vapor on the electrolyte-rich phase is set to be unity, and for the $(\beta-\alpha)$ structure the surface accommodation coefficient on the organic-rich phase is assumed to be $0.1 .^{41}$

When the electrolyte-rich phase is the shell $(\alpha-\beta), \tau_{\mathrm{hg}} \approx 10^{-5} \mathrm{~s}$ (Fig. 4b), reflecting that water uptake is essentially instantaneous. Even though full equilibration of the organic core phase will take longer, this is of minor importance in terms of change of particle mass and overall hygroscopic behavior. These conclusions apply as well to a partial engulfing morphology (Fig. 1c), where the aqueous electrolyte-rich phase maintains direct contact with the gas phase. With an organic-rich shell $(\beta-\alpha), \tau_{\mathrm{hg}}$ is controlled by the characteristic time for water to diffuse through the organic phase: $\tau_{\mathrm{hg}}$ is $\sim 10^{-3} \mathrm{~s}$ for a $50 \mathrm{~nm}$ particle; $\sim 0.1 \mathrm{~s}$ for a $300 \mathrm{~nm}$ particle; and $\sim 100 \mathrm{~s}$ for a $1 \mu \mathrm{m}$ particle. $\tau_{\mathrm{hg}}$ decreases as RH increases due to the increase of $D_{\mathrm{H}_{2} \mathrm{O}}$.

Even though the presence of a semi-solid organic phase retards water uptake, a predicted hygroscopic growth time $\tau_{\mathrm{hg}}$ on the order of seconds to minutes is still shorter than that of most atmospheric aerosol processes, especially those in the planetary boundary layer. However, a value of $\tau_{\text {hg }}$ of this order can impact results inferred from aerosol instruments with residence times of seconds, such as the hygroscopicity tandem differential mobility analyzer (HTDMA) ${ }^{15,32}$ and cloud condensation nuclei counter (CCNC). ${ }^{42}$

$D_{\mathrm{H}_{2} \mathrm{O}}$ is estimated to decrease to values as low as $10^{-20} \mathrm{~cm}^{2} \mathrm{~s}^{-1}$ at temperatures characteristic of the middle to upper troposphere, resulting in kinetic limitations of water mass transport with $\tau_{\mathrm{hg}} \approx$ hours to days. ${ }^{40,43}$ As a consequence, glassy organicinorganic aerosol particles (not fully equilibrated with the ambient RH) may act preferentially as heterogeneous ice nuclei, rather than as cloud condensation nuclei forming liquid water droplets. ${ }^{44,45}$

\section{Heterogeneous and multiphase chemistry}

Collision of vapor-phase molecules such as $\mathrm{OH}, \mathrm{O}_{3}, \mathrm{NO}_{3}, \mathrm{~N}_{2} \mathrm{O}_{5}$, and halogen radicals with organic aerosol particles induce chemical transformations that affect composition, particle size and density, and consequently optical and hygroscopic properties. ${ }^{46}$ Chemical aging of liquid-phase particles can be assumed to proceed unhindered with respect to particle-phase diffusive effects, whereas that for amorphous (semi-)solid particles is likely confined to the particle surface. ${ }^{16,47}$ For example, reactive uptake of ozone can be significantly retarded if the particle is coated with a solid organic phase. ${ }^{48}$ The presence of organic 
coatings on aqueous aerosols can suppress heterogeneous $\mathrm{N}_{2} \mathrm{O}_{5}$ hydrolysis by providing a barrier through which $\mathrm{N}_{2} \mathrm{O}_{5}$ needs to diffuse in order to undergo hydrolysis. ${ }^{49-51}$ Reactive uptake of $\mathrm{O}_{3}$ and $\mathrm{NH}_{3}$ to organic aerosols exhibits a pronounced decrease as $\mathrm{RH}$ decreases owing to the phase transformation from viscous liquid to semi-solid or amorphous solid. ${ }^{16,52}$ Therefore, the presence of a semi-solid matrix may effectively shield reactive organic compounds from chemical degradation in long-range transport. ${ }^{53}$

The multi-generation process of SOA formation involves reaction pathways of functionalization, fragmentation, and oligomerization. ${ }^{3,54}$ Physical state and morphology may influence the competition among these pathways, as fragmentation has been observed to be enhanced for solid particles compared to liquid particles. ${ }^{55,56}$ Oligomerization leads to the formation of low volatility compounds, which can enhance solidification and crust formation at the particle surface, potentially affecting reaction pathways and kinetics. ${ }^{57}$

\section{Summary and outlook}

The interplay among physical states, non-ideal mixing thermodynamics, and morphology has profound impacts on aerosol properties such as hygroscopicity and reactivity, thereby influencing gas-particle partitioning, chemical and physical transformations, cloud droplet activation and ice crystal nucleation. The common assumptions used in most of the current aerosol models, such as quasi-instantaneous gas-particle equilibrium and ideal mixing thermodynamics in organic phases need to be re-assessed. The extent of importance of non-ideal mixing and phase separation may depend strongly on carbon oxidation state, water and electrolyte contents. An amorphous semi-solid or solid state has emerged as a common feature of SOA-rich phases, especially at low relative humidity and temperature.

Detailed thermodynamic and kinetic models can be used to describe complex multi-component organic-inorganic-water systems. Quantitative measurements of viscosity and bulk diffusivity of ambient organic aerosols are challenging but essential to confirm assumptions made in models. In conclusion, the interplay of physical state, non-ideal mixing and morphology has substantial impacts on aerosol processes, and quantification of these complex effects, as a function of temperature, relative humidity, and particle composition, should be the subject of future studies.

\section{Appendix A. Gas-particle and condensed phase equilibrium model}

A thermodynamic model is used in this study to predict the compositions of gas and particle phases at stable or metastable equilibrium, constrained by given environmental conditions. The aerosol system considered consists of SOA from the oxidation of $\alpha$-pinene by ozone, ammonium sulfate (AS) as inorganic electrolyte, and water. For the coupled gas-particle partitioning, liquid-liquid phase separation, and solid-liquid equilibria computations, we use a slightly modified version of the MCM-EVAPORATION-AIOMFAC approach introduced by Zuend and Seinfeld. ${ }^{6} \alpha$-pinene SOA is represented using a set of 12 semivolatile or low-volatility organic compounds, as predicted by the Master Chemical Mechanism (MCM v3.1), ${ }^{58,59}$ with the addition of two extremely low-volatility dimer species, which reside essentially entirely in the condensed phase. The molecular structures, molar yields, and pure component vapor pressures of the selected SOA products are given in Table 1. Molar yields of the selected oxidation products are taken from the MCM prediction and assumed to be constant over the relative humidity range and parent hydrocarbon loading levels considered. The EVAPORATION model (Estimation of VApour Pressure of ORganics, Accounting for Temperature, Intramolecular, and Non-additivity effects), ${ }^{60}$ an advanced group-contribution method, is used to calculate pure component (liquid state) vapor pressures of the organic SOA compounds at a temperature of $298 \mathrm{~K}$. The gas phase is treated as an ideal gas mixture. Non-ideal thermodynamic mixing in the condensed phase is considered via composition-dependent activity coefficients, calculated with the AIOMFAC model (Aerosol Inorganic-Organic Mixtures Functional groups Activity Coefficients). ${ }^{29,30}$ This group-contribution model explicitly considers interactions between all components (and their functional groups) present in a mixture, including interactions between dissolved inorganic ions and organic functional groups.

Overall gas-particle partitioning is calculated using modified Raoult's law (known as absorptive partitioning with consideration of non-ideality ${ }^{27,61,62}$ ), based on the method described by Zuend et al. ${ }^{6,63}$ This method describes the gasparticle system as a semi-closed vapor-liquid equilibrium, in which the overall composition of organic compounds and ammonium sulfate is held fixed, while the absolute amount of water in the system depends on the given $\mathrm{RH}$ level and temperature. A system of nonlinear equations is then solved to find the partitioning of each component between the gas and particle phases. ${ }^{63}$ The particle "phase" itself is treated as a liquid (potentially viscous) that may be in equilibrium with a solid (crystalline) AS phase and/or a second liquid phase in the case of liquid-liquid phase separation. This requires solving additional systems of nonlinear equations to minimize the total Gibbs energy of the gas-particle system. The potential for a liquid-liquid phase separation is accounted for and corresponding phase compositions are calculated with the practical method of Zuend and Seinfeld. ${ }^{28}$ Solid-liquid equilibrium between crystalline and dissolved AS is calculated based on the conditions of a constant ion activity product (IAP) of a saturated solution in equilibrium with a solid phase at given temperature: ${ }^{30} \operatorname{IAP}\left[\left(\mathrm{NH}_{4}\right)_{2} \mathrm{SO}_{4}\right]=\left[a^{(\mathrm{m})}\left(\mathrm{NH}_{4}{ }^{+}\right)\right]^{2} \times\left[a^{(\mathrm{m})}\left(\mathrm{SO}_{4}{ }^{2-}\right)\right]=$ $\mathrm{IAP}_{\text {sat }}\left[\left(\mathrm{NH}_{4}\right)_{2} \mathrm{SO}_{4}\right]$. Here, $a^{(\mathrm{m})}\left(\mathrm{NH}_{4}{ }^{+}\right)$and $a^{(\mathrm{m})}\left(\mathrm{SO}_{4}{ }^{2-}\right)$ are molality-based activities of the cation and anion, respectively. A reference value for $\operatorname{IAP}_{\text {sat }}\left[\left(\mathrm{NH}_{4}\right)_{2} \mathrm{SO}_{4}\right]$ is calculated from the measured solubility limit of AS in water (at the same temperature). ${ }^{64}$ 
In the case of the aerosol system shown in Fig. 1, the kinetic process of efflorescence (crystallization upon drying) of AS is assumed to occur rapidly at a supersaturation of $\sim 25 \times$ $\mathrm{IAP}_{\text {sat }}\left[\left(\mathrm{NH}_{4}\right)_{2} \mathrm{SO}_{4}\right]$, corresponding to a typical supersaturation level at efflorescence observed for micrometer-sized (aqueous) ammonium sulfate particles. ${ }^{65}$ In highly viscous solution droplets, the formation of a crystalline nucleus and subsequent growth of the solid phase may be inhibited due to kinetic mass transfer limitations to the point where efflorescence may be suppressed completely, even at very high salt supersaturation (at low RH). ${ }^{15,66}$ However, in the aerosol system of this study, liquid-liquid phase separation occurs at high RH already (see Fig. 2 of the main text) and AS resides predominantly in an aqueous electrolyte-rich phase, which is expected to maintain a relatively low viscosity, leading to the crystallization of AS typically at a $\mathrm{RH}$ range between $\sim 30 \%$ to $40 \%{ }^{13}$ Fig. 5 shows the activity coefficients of the organic components and of water in the two coexisting phases corresponding to Fig. $2 \mathrm{c}$ and $\mathrm{d}$ resulting from the partitioning calculations with the AIOMFAC model. The salting-out effect of the concentrated aqueous AS solution characterizing phase $\alpha$ leads to very large activity coefficient values of the organic components, which are therefore present in that phase only in negligible amounts over most of the $\mathrm{RH}$ range. In contrast, the variation of the activity coefficients of water in both phases is relatively small. Hence, in terms of mole fractions, water is present in both phases to a significant degree.

For the purpose of model predictions with realistic values mimicking conditions in the lower troposphere, in this study the total amount of parent hydrocarbon ( $\alpha$-pinene) and AS are chosen such that the resulting dry mass ratio of the SOA fraction/AS is $\sim 1.5$ (range: 1.33 to 1.83 for $30 \%$ to $99 \% \mathrm{RH}$ ). The SOA mass ranges from $\sim 1.7 \mu \mathrm{g} \mathrm{m}^{-3}$ to $\sim 2.4 \mu \mathrm{g} \mathrm{m}^{-3}$ for $10^{-7} \mathrm{~mol} \mathrm{~m}^{-3}\left(\sim 2.45 \mathrm{ppb}_{\mathrm{v}}\right)$ of $\alpha$-pinene reacted.

For the calculation of the metastable branch of a humidity cycle in the composition range between the deliquescence and efflorescence of the salt (see Fig. 1), the formation of a solid salt phase in equilibrium with a saturated liquid solution is disabled in the model, allowing for gas-particle partitioning predictions in the case of liquid phases supersaturated with respect to dissolved AS. The predicted mass growth factor curves (humidity cycle) for the $\alpha$-pinene SOA + AS + water system (Fig. 1) shows a sharp transition at the deliquescence point of AS, indicating that the amount of AS dissolved in the organic-rich phase is minuscule and does not lead to a noticeable water uptake prior to deliquescence. Note that this behavior can be quite different for systems containing highly oxidized organic compounds, such as citric acid, ${ }^{67}$ and will also depend on the ratio of organic/inorganic portions.

In contrast to mass growth factors owing to water uptake by nearly nonvolatile solutes (such as pure AS), the mass growth factor curve of the organic-inorganic system shown in Fig. 1 includes as well enhanced partitioning of gas-phase organic components to the particle phase as RH increases. This is also shown in Fig. 2d for the partitioning of individual organic compounds and their cumulative contribution to the particle mass as a function of RH. This effect on the overall mass growth factor, aside from the $\mathrm{RH}$-dependent water uptake, is also dependent on the total organic concentration. For the studied system it means that the mass growth factor relative to the initial particle size on the stable humidity cycle branch (solid AS below deliquescence of AS), e.g. at 75\% $\mathrm{RH}$, is larger for lower $\alpha$-pinene SOA concentrations, since the additional mass owing to water uptake and slightly increased organic contributions for high SOA concentrations is small relative to the dry mass at $0 \% \mathrm{RH}$ (the baseline for mass growth factor normalization). Therefore, combined water and organic uptake may be of importance regarding comparison of laboratory and field measurements of aerosol hygroscopic growth factors at different SOA concentration levels.
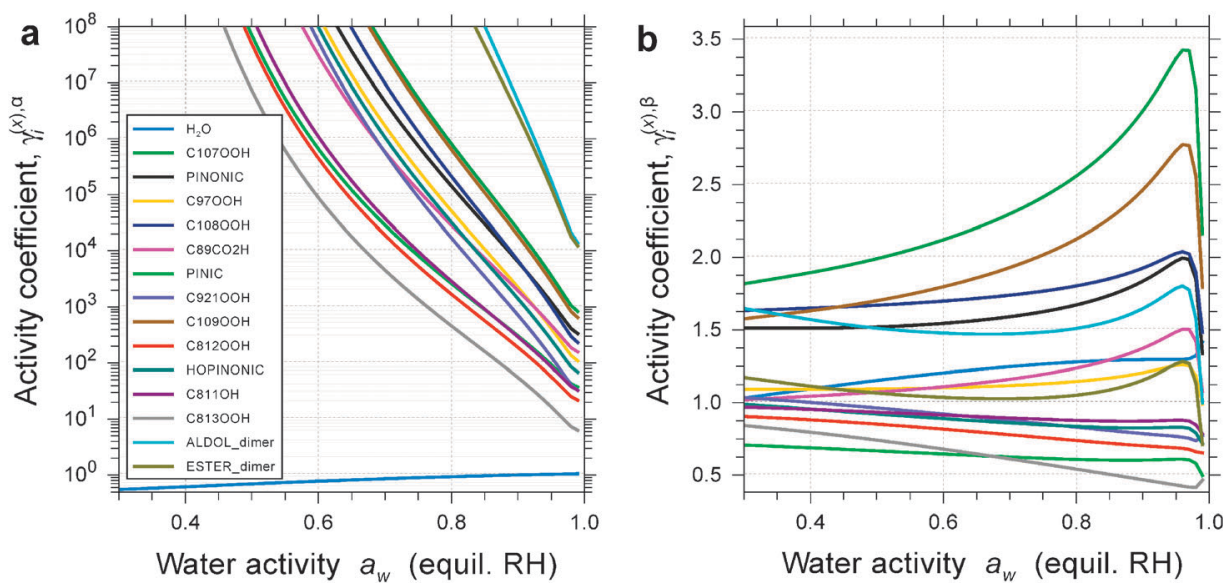

Fig. 5 Predicted mole fraction-based activity coefficients of water and organic components in the two liquid phases of the $\alpha$-pinene SOA + AS + water system as a function of RH at gas-particle equilibrium at $298 \mathrm{~K}$. (a) Activity coefficients in the aqueous electrolyte-rich phase $\alpha$ (logarithmic scale). The SOA compound structures corresponding to the listed names are given in Table 1. (b) Activity coefficients in the organic-rich phase $\beta$ (linear scale). The large values of organic activity coefficients in phase $\alpha$ arise from the rather hydrophobic nature of most organic components and their unfavorable mixing with a concentrated aqueous electrolyte solution. 


\section{Appendix B. KM-GAP-AIOMFAC model description}

KM-GAP (kinetic multi-layer model of gas-particle interactions in aerosols and clouds) ${ }^{35}$ consists of multiple model compartments and layers including gas phase, surface sorption layer and $L$ bulk layers. Phase $\beta$, a predominantly organic phase, consists of a surface layer and $m$ bulk layers. Phase $\alpha$, an aqueous electrolyte-rich phase, consists of $L-m$ layers. In the present simulation, parameters $L=12$ and $m=10$ are used. Note that the simulated results are not sensitive to the choice of these values if $m \geq 3$. The following processes are explicitly treated: gas-phase diffusion, gas-surface transport, surfacebulk exchange, bulk diffusion, and exchange between two phases. The detailed formalisms for each process are described in the following subsections.

\section{B.1 Gas phase diffusion and gas-surface transport}

The thickness of the near-surface gas-phase layer is set to be the average mean free path $\lambda$ of vapor species. Based on Fick's law, the gas-phase diffusion flux of species $i, J_{\text {diff, } z_{i}}$, is described as, ${ }^{68}$

$$
J_{\text {diff }, Z_{i}}=2 \pi\left(D_{\mathrm{p}}+2 \lambda\right) D_{\mathrm{g}, \mathrm{Z}_{i}}\left(\left[\mathrm{Z}_{i}\right]_{\mathrm{g}}-\left[\mathrm{Z}_{i}\right]_{\mathrm{gs}}\right),
$$

where $D_{\mathrm{p}}$ is the particle diameter, $D_{\mathrm{g}, \mathrm{Z}_{i}}$ is the gas-phase diffusion coefficient, and $\left[\mathrm{Z}_{i}\right]_{\mathrm{g}}$ and $\left[\mathrm{Z}_{i}\right]_{\mathrm{gs}}$ are the number concentrations of species $i$ in the gas-phase and the near-gas phase layers, respectively. $D_{\mathrm{g}, \mathrm{Z}_{i}}$ of organic components are assumed to be $0.05 \mathrm{~cm}^{2} \mathrm{~s}^{-1} \cdot 69,70$

Adsorption and desorption fluxes $\left(J_{\mathrm{ads}, \mathrm{Z}_{i}}, J_{\mathrm{des}, \mathrm{Z}_{i}}\right)$ are described as,

$$
\begin{gathered}
J_{\mathrm{ads}, \mathrm{Z}_{i}}=\alpha_{\mathrm{s}, \mathrm{Z}_{i}} J_{\text {coll }, \mathrm{Z}_{i}}=\alpha_{\mathrm{s}, \mathrm{Z}_{i}}\left[\mathrm{Z}_{i}\right]_{\mathrm{gs}} \omega_{\mathrm{Z}_{i}} / 4=k_{\mathrm{a}, \mathrm{Z}_{i}}\left[\mathrm{Z}_{i}\right]_{\mathrm{gs}} \\
J_{\text {des }, \mathrm{Z}_{i}}=k_{\mathrm{d}, \mathrm{Z}_{i}} \gamma_{i}^{\beta}\left[\mathrm{Z}_{i}\right]_{\mathrm{s}}=\tau_{\mathrm{d}, \mathrm{Z}_{i}}{ }^{-1} \gamma_{i}^{\beta}\left[\mathrm{Z}_{i}\right]_{\mathrm{s}}
\end{gathered}
$$

where $\alpha_{\mathrm{s}, \mathrm{Z}_{i}}$ is the surface accommodation coefficient, $\omega_{\mathrm{Z}_{i}}$ is the mean thermal velocity, $k_{\mathrm{a}, \mathrm{Z}_{i}}$ and $k_{\mathrm{d}, \mathrm{z}_{i}}$ are the adsorption and desorption coefficients, respectively, $\tau_{\mathrm{d}, \mathrm{z}_{i}}$ is the desorption lifetime, and $\left[Z_{i}\right]_{\mathrm{s}}$ is the surface concentration. $\gamma_{i}^{\beta}$ is the mole fraction-based activity coefficient of species $i$ in phase $\beta$, which is provided by the AIOMFAC model. ${ }^{29,30} \tau_{\mathrm{d}, \mathrm{z}_{i}}$ is assumed to be $10^{-9} \mathrm{S.}^{71}$

\section{B.2 Surface-bulk change}

The transport of species $i$ between sorption layer and surface layer $\left(J_{\mathrm{s}, \mathrm{ss}, \mathrm{Z}_{i}}\right.$ and $\left.J_{\mathrm{ss}, \mathrm{s}, \mathrm{Z}_{i}}\right)$ is described as,

$$
\begin{aligned}
& J_{\mathrm{s}, \mathrm{ss}, \mathrm{Z}_{i}}=k_{\mathrm{s}, \mathrm{ss}, \mathrm{Z}_{i}}\left[\mathrm{Z}_{i}\right]_{\mathrm{s}} \gamma_{i}^{\beta} \\
& J_{\mathrm{ss}, \mathrm{s}, \mathrm{Z}_{i}}=k_{\mathrm{ss}, \mathrm{s}, \mathrm{Z}_{i}}\left[\mathrm{Z}_{i}\right]_{\mathrm{ss}} \gamma_{i}^{\beta}
\end{aligned}
$$

where $k_{\mathrm{s}, \mathrm{ss}, \mathrm{Z}_{i}}$ and $k_{\mathrm{ss}, \mathrm{s}, \mathrm{Z}_{i}}$ are the first-order transport rate coefficients. Estimates for $k_{\mathrm{ss}, \mathrm{s}, \mathrm{Z}_{i}}$ can be derived from the corresponding bulk diffusion coefficients in phase $\beta, D_{\mathrm{b}, Z_{i}}^{\beta}$, based on Fick's first law of diffusion considering that a molecule $i$ in the sorption layer, on average, needs to travel a distance of
$\left(\delta_{\mathrm{Z}_{i}}+\delta_{\mathrm{ss}}\right) / 2$ to move from the sorption layer (thickness: $\left.\delta_{\mathrm{Z}_{i}}\right)$ to the quasi-static surface layer (thickness: $\delta_{\mathrm{ss}}$ ):

$$
k_{\mathrm{ss}, \mathrm{s}, \mathrm{Z}_{i}} \approx 2 D_{\mathrm{b}, \mathrm{Z}_{i}}^{\beta} /\left(\delta_{\mathrm{Z}_{i}}+\delta_{\mathrm{ss}}\right)
$$

An estimate for $k_{\mathrm{s}, \mathrm{ss}, \mathrm{Z}_{i}}$ can be determined considering mass transport at equilibrium. Mass balance implies that $k_{\mathrm{s}, \mathrm{ss}, \mathrm{Z}_{i}}\left[\mathrm{Z}_{i}\right]_{\mathrm{s}, \mathrm{eq}} \gamma_{i}^{\beta}=k_{\mathrm{ss}, \mathrm{s}, \mathrm{Z}_{i}}\left[\mathrm{Z}_{i}\right]_{\mathrm{ss}, \mathrm{eq}} \gamma_{i}^{\beta}$, i.e., $J_{\mathrm{s}, \mathrm{ss}, \mathrm{Z}_{i}}=J_{\mathrm{ss}, \mathrm{s}, \mathrm{Z}_{i}}$, and $k_{\mathrm{d}, \mathrm{Z}_{i}}\left[\mathrm{Z}_{i}\right]_{\mathrm{s}, \mathrm{eq}} \gamma_{i}^{\beta}=$ $k_{\mathrm{a}, \mathrm{Z}_{i}}\left[\mathrm{Z}_{i}\right]_{\mathrm{g} \text {,eq }}$, i.e., $J_{\mathrm{des}, \mathrm{Z}_{i}}=J_{\mathrm{ads}, \mathrm{Z}_{i}}$, where $\left[\mathrm{Z}_{i}\right]_{\mathrm{g}, \mathrm{eq}},\left[\mathrm{Z}_{i}\right]_{\mathrm{s} \text {,eq }}$, and $\left[\mathrm{Z}_{i}\right]_{\mathrm{ss} \text {,eq }}$ are the equilibrium number concentrations of $Z_{i}$ in the gas phase, on the sorption layer, and in the quasi-static surface layer, respectively. This leads to

$$
k_{\mathrm{s}, \mathrm{ss}, \mathrm{Z}_{i}} \approx k_{\mathrm{ss}, \mathrm{s}, \mathrm{Z}_{i}} \frac{k_{\mathrm{d}, \mathrm{Z}_{i}}}{k_{\mathrm{a}, \mathrm{Z}_{i}}} \frac{\left[\mathrm{Z}_{i}\right]_{\mathrm{ss}, \mathrm{eq}} \gamma_{i}^{\beta}}{\left[\mathrm{Z}_{i}\right]_{\mathrm{g}, \mathrm{eq}}}
$$

$\left[\mathrm{Z}_{i}\right]_{\mathrm{ss} \text {,eq }}$ and $\left[\mathrm{Z}_{i}\right]_{\mathrm{g} \text {,eq }}$ can be provided by the thermodynamic gas-particle partitioning model based on AIOMFAC. From the ideal gas law $\left[\mathrm{Z}_{i}\right]_{\mathrm{g}, \mathrm{eq}}$ is,

$$
\left[\mathrm{Z}_{i}\right]_{\mathrm{g}, \mathrm{eq}}=\frac{p_{\mathrm{Z}_{i}}^{\mathrm{eq}} N_{\mathrm{A}}}{R T_{\mathrm{s}}}
$$

where $p_{\mathrm{Z}_{i}}^{\mathrm{eq}}$ is the equilibrium vapor pressure of species $i$ over the condensed mixture. Based on modified Raoult's law applied to a two-phase liquid-liquid equilibrium, $p_{\mathrm{Z}_{i}}^{\mathrm{eq}}$ is,

$$
p_{\mathrm{Z}_{i}}^{\mathrm{eq}}=p_{\mathrm{Z}_{i}}^{\mathrm{o}} x_{\mathrm{Z}_{i}}^{\beta} \gamma_{i}^{\beta}=p_{\mathrm{Z}_{i}}^{\mathrm{o}} x_{\mathrm{Z}_{i}}^{\alpha} \gamma_{i}^{\alpha}
$$

where $p_{Z_{i}}^{o}$ is saturation vapor pressure of pure (liquid, subcooled) compound $i$, and $x_{\mathrm{Z}_{i}}$ is the mole fraction of compound $i$. Component's activities in phases $\alpha$ and $\beta$ are the same at equilibrium $\left(x_{Z_{i}}^{\beta} \gamma_{i}^{\beta}=x_{Z_{i}}^{\alpha} \gamma_{i}^{\alpha}\right)$. Mole fractions and activity coefficients in the different phases at equilibrium are estimated by the AIOMFAC-based gas-particle partitioning model.

\section{B.3 Bulk diffusion}

Bulk diffusion is explicitly treated as the mass transport $\left(J_{\mathrm{b}_{j}, \mathrm{~b}_{j \pm 1}}\right)$ from one discrete layer (bulk $j$ ) to the next (bulk $j \pm 1$ ). By analogy to surface-bulk mass transport, we describe the mass transport fluxes between different layers of the bulk using the first-order transport rate coefficient $k_{\mathrm{b}_{j} \mathrm{~b}_{j \pm 1}, \mathrm{z}_{i}}$,

$$
\begin{gathered}
J_{\mathrm{b}_{j} \mathrm{~b}_{j \pm 1}, \mathrm{z}_{i}}=k_{\mathrm{b}_{j} \mathrm{~b}_{j \pm 1}, \mathrm{z}_{i}}\left[\mathrm{Z}_{i}\right]_{\mathrm{b}_{j}} \gamma_{i}^{\pi}(\pi=\alpha \text { or } \beta) \\
k_{\mathrm{b}_{j} \mathrm{~b}_{j \pm 1}, \mathrm{z}_{i}}=2 D_{\mathrm{b}, \mathrm{z}_{i}} /(\delta(j)+\delta(j+1))
\end{gathered}
$$

Mass transport fluxes between phase $\alpha$ and $\beta\left(J_{\alpha, \beta}\right.$ and $\left.J_{\beta, \alpha}\right)$ can be described as,

$$
\begin{gathered}
J_{\alpha, \beta, \mathrm{Z}_{i}}=k_{\alpha, \beta, \mathrm{Z}_{i}}\left[\mathrm{Z}_{i}\right]_{\mathrm{b} m} \gamma_{i}^{\alpha} \\
J_{\beta, \alpha, \mathrm{Z}_{i}}=k_{\beta, \alpha, \mathrm{Z}_{i}}\left[\mathrm{Z}_{i}\right]_{\mathrm{b} m-1} \gamma_{i}^{\beta}
\end{gathered}
$$

where $k_{\alpha, \beta}$ and $k_{\beta, \alpha}$ are exchange rate coefficients between phases $\alpha$ and $\beta$, respectively. Note that activity coefficients $\gamma_{i}^{\pi}$ are mole fraction-based and $\left[\mathrm{Z}_{i}\right]_{\mathrm{b}_{j}}$ is molecule number-based. Activity coefficients $\gamma_{i}^{\pi}$ are used to correct $\left[\mathrm{Z}_{i}\right]_{\mathrm{b}_{j}}$ since they are directly related to the mole fractions of compounds in the bulk layer $j, x_{i, \mathrm{~b}_{j}}:\left[\mathrm{Z}_{i}\right]_{\mathrm{b}_{j}}=x_{i, \mathrm{~b}_{j}} n_{\mathrm{b}_{j}} N_{\mathrm{A}} / V_{\mathrm{b}_{j}}$, where $n_{\mathrm{b}_{j}}$ is total 
moles in the bulk layer $j, N_{\mathrm{A}}$ is the Avogadro's number, and $V_{\mathrm{b}_{j}}$ is the volume of the bulk layer $j$. Here $k_{\alpha, \beta}$ is estimated considering bulk diffusion in the interfacial layers of phases $\alpha$ and $\beta$,

$$
k_{\alpha, \beta, Z_{i}}=2\left(D_{\mathrm{b}, Z_{i}}^{\beta} / \delta(j-1)+D_{\mathrm{b}, Z_{i}}^{\alpha} / \delta(j)\right)
$$

An estimate for $k_{\beta, \alpha, z_{i}}$ can be determined considering mass transport between two phases at equilibrium. Mass balance implies that $k_{\alpha, \beta, \mathrm{Z}_{i}}\left[\mathrm{Z}_{i}\right]_{\mathrm{b} m+1, \mathrm{eq}} \gamma_{i}^{\alpha}=k_{\beta, \alpha, \mathrm{Z}_{i}}\left[\mathrm{Z}_{i}\right]_{\mathrm{b} m, \mathrm{eq}} \gamma_{i}^{\beta}$; i.e., $J_{\alpha, \beta, \mathrm{Z}_{i}}=$ $J_{\beta, \alpha, \mathrm{Z}_{i}}\left[\mathrm{Z}_{i}\right]_{\mathrm{b} m+1, \mathrm{eq}}$ and $\left[\mathrm{Z}_{i}\right]_{\mathrm{b} m, \text { eq }}$ are number concentrations of $\mathrm{Z}_{i}$ at equilibrium in phases $\alpha$ and $\beta$, respectively, which can be provided by an equilibrium partitioning computation,

$$
k_{\beta, \alpha, \mathrm{Z}_{i}}=k_{\alpha, \beta, \mathrm{Z}_{i}}\left[\mathrm{Z}_{i}\right]_{\mathrm{b} m+1, \mathrm{eq}} \gamma_{i}^{\alpha} /\left[\mathrm{Z}_{i}\right]_{\mathrm{b} m-1, \mathrm{eq}} \gamma_{i}^{\beta}
$$

In summary, the AIOMFAC-based gas-particle partitioning and liquid-liquid phase separation model provides component activity coefficients, liquid-phase mole fractions, and the overall molar (or mass) distribution between gas and particle phases at equilibrium. This informations is used in KM-GAP to constrain kinetic parameters. In this way, offline coupling of AIOMFAC and KM-GAP is achieved. The dynamics of compound concentrations in the gas and particle phases and of the particle size were computed by solving the mass balance and transfer rate equations (Fig. 6).

\section{Appendix C. Estimation of $D_{\mathrm{H}_{2} \mathrm{O}}$ in SOA}

The diffusion coefficient of water $\left(D_{\mathrm{H}_{2} \mathrm{O}}\right)$ in $\alpha$-pinene SOA is estimated using percolation theory. ${ }^{72,73}$ Note that for the estimation of $D_{\mathrm{H}_{2} \mathrm{O}}$ the Stokes-Einstein equation is not applicable for small gas molecules diffusing through a semi-solid matrix near the glass transition temperature. ${ }^{16,17,73,74}$ According to percolation and effective medium theory, the average diffusion coefficient in a mixture of two media with different diffusion coefficients can be described by the following equation: ${ }^{73}$

$$
\begin{aligned}
D_{\mathrm{H}_{2} \mathrm{O}}= & {\left[D_{\mathrm{H}_{2} \mathrm{O}, \mathrm{SOA}^{\prime}}+D_{\mathrm{H}_{2} \mathrm{O}, \mathrm{H}_{2} \mathrm{O}}{ }^{\prime}+\left[\left(D_{\mathrm{H}_{2} \mathrm{O}, \mathrm{SOA}^{\prime}}+D_{\mathrm{H}_{2} \mathrm{O}, \mathrm{H}_{2} \mathrm{O}}{ }^{\prime}\right)^{2}\right.\right.} \\
& \left.\left.+2(Z-2) D_{\mathrm{H}_{2} \mathrm{O}, \mathrm{SOA}} D_{\mathrm{H}_{2} \mathrm{O}, \mathrm{H}_{2} \mathrm{O}}\right]^{0.5}\right] /(Z-2)
\end{aligned}
$$

where $D_{\mathrm{H}_{2} \mathrm{O}, \mathrm{SOA}}$ is the diffusion coefficient of water in water-free SOA, and $D_{\mathrm{H}_{2} \mathrm{O}, \mathrm{H}_{2} \mathrm{O}}$ is the self-diffusion coefficient of water in water $\left(\sim 10^{-5} \mathrm{~cm}^{2} \mathrm{~s}^{-1}\right) . D_{\mathrm{H}_{2} \mathrm{O}, \mathrm{SOA}}{ }^{\prime}$ and $D_{\mathrm{H}_{2} \mathrm{O}, \mathrm{H}_{2} \mathrm{O}}{ }^{\prime}$ are reduced diffusion coefficients and are expressed as,

$$
\begin{aligned}
& D_{\mathrm{H}_{2} \mathrm{O}, \mathrm{SOA}^{\prime}}=\left[(Z / 2)\left(V_{\mathrm{p}, \mathrm{SOA}} / f\right)-1\right] D_{\mathrm{H}_{2} \mathrm{O}, \mathrm{SOA}} \\
& D_{\mathrm{H}_{2} \mathrm{O}, \mathrm{H}_{2} \mathrm{O}}{ }^{\prime}=\left[(Z / 2)\left(V_{\mathrm{p}, \mathrm{H}_{2} \mathrm{O}} / f\right)-1\right] D_{\mathrm{H}_{2} \mathrm{O}, \mathrm{H}_{2} \mathrm{O}}
\end{aligned}
$$

$V_{\mathrm{p}, \mathrm{SOA}}$ and $V_{\mathrm{p}, \mathrm{H}_{2} \mathrm{O}}$ are the volume fractions of SOA and $\mathrm{H}_{2} \mathrm{O}$, respectively, which can be provided by AIOMFAC as shown in Fig. 2. $f$ is the packing fraction, for which we assume a value of $0.85 .^{75} \mathrm{Z}$ is the coordination number between water-filled pores

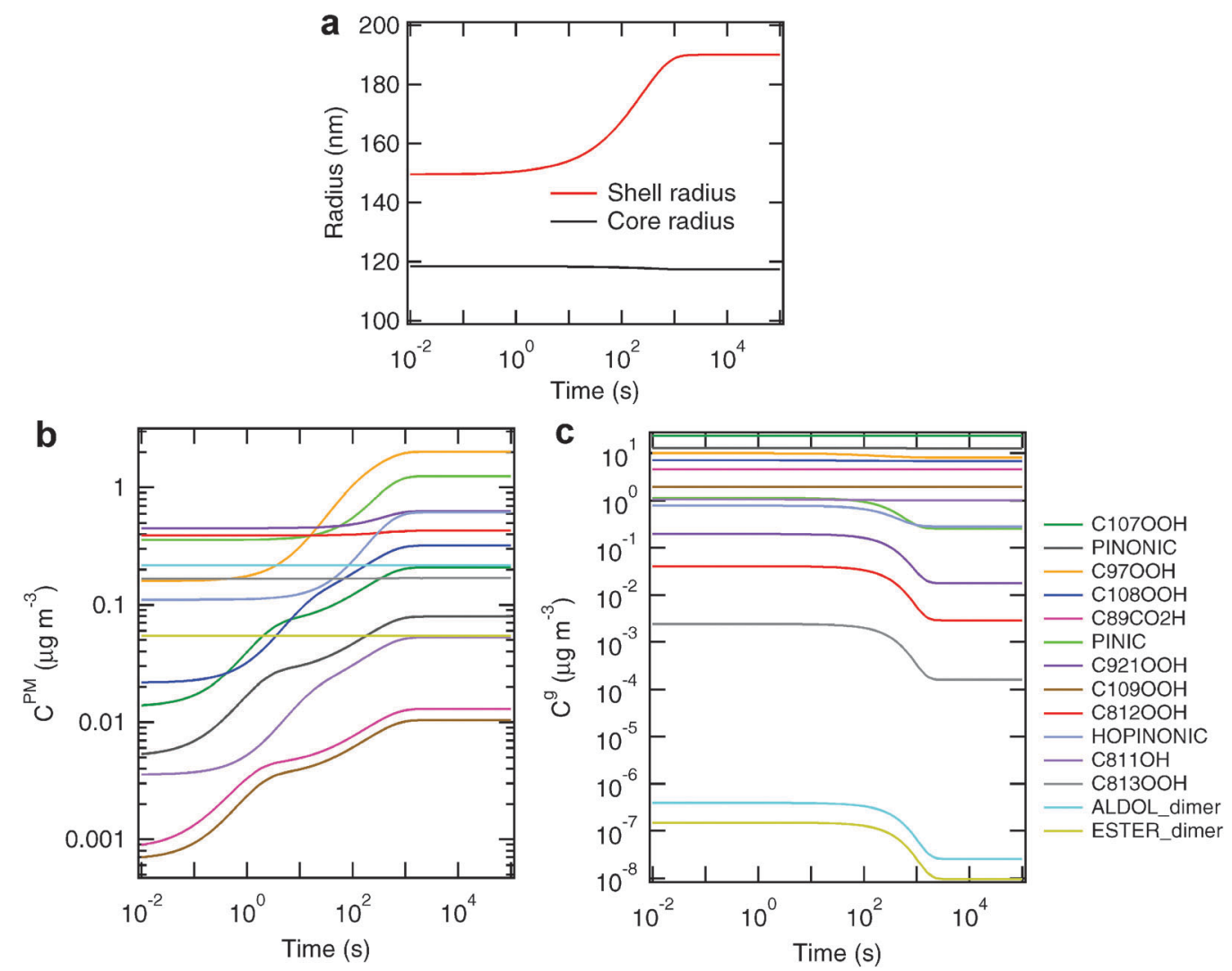

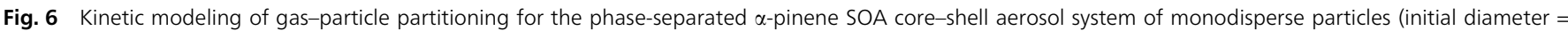

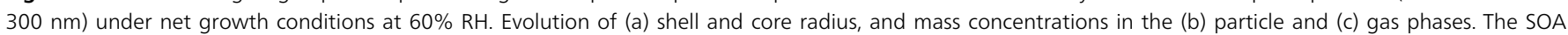
compound structures corresponding to the listed names are given in Table 1. 
in SOA, for which we assume a value of 12 that is characteristic for dense sphere packings. ${ }^{76}$ As no direct measurements of $D_{\mathrm{H}_{2} \mathrm{O}, \mathrm{SOA}}$ are available, we assume $10^{-12}-10^{-8} \mathrm{~cm}^{2} \mathrm{~s}^{-1}$, which is in the range of observed bulk diffusivity of water in aqueous sucrose glasses at room temperature. ${ }^{40}$ For uncertainty estimates (green shaded area in Fig. 4a), $f$ was varied from 0.65 to $1^{73,75,77}$ and $Z$ was varied between 8 and $16^{73}$

\section{Acknowledgements}

This work was funded by US National Science Foundation grant AGS-1057183. MS was supported by the Japan Society for the Promotion of Science (JSPS) Postdoctoral Fellowship for Research Abroad.

\section{References}

1 U. Pöschl, Angew. Chem., Int. Ed., 2005, 44, 7520-7540.

2 IPCC, Climate Change 2007: The Physical Science Basis. Contribution of Working Group 1 to the 4th Assessment Report of the IPCC, Cambridge University Press, Cambridge, UK, 2007.

3 J. L. Jimenez, M. R. Canagaratna, N. M. Donahue, A. S. H. Prevot, Q. Zhang, J. H. Kroll, P. F. DeCarlo, J. D. Allan, H. Coe, N. L. Ng, A. C. Aiken, K. S. Docherty, I. M. Ulbrich, A. P. Grieshop, A. L. Robinson, J. Duplissy, J. D. Smith, K. R. Wilson, V. A. Lanz, C. Hueglin, Y. L. Sun, J. Tian, A. Laaksonen, T. Raatikainen, J. Rautiainen, P. Vaattovaara, M. Ehn, M. Kulmala, J. M. Tomlinson, D. R. Collins, M. J. Cubison, E. J. Dunlea, J. A. Huffman, T. B. Onasch, M. R. Alfarra, P. I. Williams, K. Bower, Y. Kondo, J. Schneider, F. Drewnick, S. Borrmann, S. Weimer, K. Demerjian, D. Salcedo, L. Cottrell, R. Griffin, A. Takami, T. Miyoshi, S. Hatakeyama, A. Shimono, J. Y. Sun, Y. M. Zhang, K. Dzepina, J. R. Kimmel, D. Sueper, J. T. Jayne, S. C. Herndon, A. M. Trimborn, L. R. Williams, E. C. Wood, A. M. Middlebrook, C. E. Kolb, U. Baltensperger and D. R. Worsnop, Science, 2009, 326, 1525-1529.

4 M. Hallquist, J. C. Wenger, U. Baltensperger, Y. Rudich, D. Simpson, M. Claeys, J. Dommen, N. M. Donahue, C. George, A. H. Goldstein, J. F. Hamilton, H. Herrmann, T. Hoffmann, Y. Iinuma, M. Jang, M. E. Jenkin, J. L. Jimenez, A. Kiendler-Scharr, W. Maenhaut, G. McFiggans, T. F. Mentel, A. Monod, A. S. H. Prevot, J. H. Seinfeld, J. D. Surratt, R. Szmigielski and J. Wildt, Atmos. Chem. Phys., 2009, 9, 5155-5235.

5 E. I. Chang and J. F. Pankow, Atmos. Environ., 2006, 40, 6422-6436.

6 A. Zuend and J. H. Seinfeld, Atmos. Chem. Phys., 2012, 12, 3857-3882.

7 N. O. A. Kwamena, J. Buajarern and J. P. Reid, J. Phys. Chem. A, 2010, 114, 5787-5795.

8 A. K. Bertram, S. T. Martin, S. J. Hanna, M. L. Smith, A. Bodsworth, Q. Chen, M. Kuwata, A. Liu, Y. You and S. R. Zorn, Atmos. Chem. Phys., 2011, 11, 10995-11006.
9 J. P. Reid, B. J. Dennis-Smither, N. O. A. Kwamena, R. E. H. Miles, K. L. Hanford and C. J. Homer, Phys. Chem. Chem. Phys., 2011, 13, 15559-15572.

10 M. Song, C. Marcolli, U. K. Krieger, A. Zuend and T. Peter, Atmos. Chem. Phys., 2012, 12, 2691-2712.

11 M. Song, C. Marcolli, U. K. Krieger, A. Zuend and T. Peter, Geophys. Res. Lett., 2012, 39, L19801.

12 C. Pöhlker, K. T. Wiedemann, B. Sinha, M. Shiraiwa, S. S. Gunthe, M. Smith, H. Su, P. Artaxo, Q. Chen, Y. Cheng, W. Elbert, M. K. Gilles, A. L. D. Kilcoyne, R. C. Moffet, M. Weigand, S. T. Martin, U. Pöschl and M. O. Andreae, Science, 2012, 337, 1075-1078.

13 Y. You, L. Renbaum-Wolff, M. Carreras-Sospedra, S. J. Hanna, N. Hiranuma, S. Kamal, M. L. Smith, X. L. Zhang, R. J. Weber, J. E. Shilling, D. Dabdub, S. T. Martin and A. K. Bertram, Proc. Natl. Acad. Sci. U. S. A., 2012, 109, 13188-13193.

14 B. Zobrist, C. Marcolli, D. A. Pedernera and T. Koop, Atmos. Chem. Phys., 2008, 8, 5221-5244.

15 E. Mikhailov, S. Vlasenko, S. T. Martin, T. Koop and U. Pöschl, Atmos. Chem. Phys., 2009, 9, 9491-9522.

16 M. Shiraiwa, M. Ammann, T. Koop and U. Pöschl, Proc. Natl. Acad. Sci. U. S. A., 2011, 108, 11003-11008.

17 T. Koop, J. Bookhold, M. Shiraiwa and U. Pöschl, Phys. Chem. Chem. Phys., 2011, 13, 19238-19255.

18 A. Virtanen, J. Joutsensaari, T. Koop, J. Kannosto, P. YliPirilä, J. Leskinen, J. M. Mäkelä, J. K. Holopainen, U. Pöschl, M. Kulmala, D. R. Worsnop and A. Laaksonen, Nature, 2010, 467, 824-827.

19 E. Saukko, A. T. Lambe, P. Massoli, T. Koop, J. P. Wright, D. R. Croasdale, D. A. Pedernera, T. B. Onasch, A. Laaksonen, P. Davidovits, D. R. Worsnop and A. Virtanen, Atmos. Chem. Phys., 2012, 12, 7517-7529.

20 C. D. Cappa and K. R. Wilson, Atmos. Chem. Phys., 2011, 11, 1895-1911.

21 T. D. Vaden, D. Imre, J. Beranek, M. Shrivastava and A. Zelenyuk, Proc. Natl. Acad. Sci. U. S. A., 2011, 108, 2190-2195.

22 M. Kalberer, D. Paulsen, M. Sax, M. Steinbacher, J. Dommen, A. S. H. Prevot, R. Fisseha, E. Weingartner, V. Frankevich, R. Zenobi and U. Baltensperger, Science, 2004, 303, 1659-1662.

23 M. Kanakidou, J. H. Seinfeld, S. N. Pandis, I. Barnes, F. J. Dentener, M. C. Facchini, R. Van Dingenen, B. Ervens, A. Nenes, C. J. Nielsen, E. Swietlicki, J. P. Putaud, Y. Balkanski, S. Fuzzi, J. Horth, G. K. Moortgat, R. Winterhalter, C. E. L. Myhre, K. Tsigaridis, E. Vignati, E. G. Stephanou and J. Wilson, Atmos. Chem. Phys., 2005, 5, 1053-1123.

24 G. McFiggans, D. O. Topping and M. H. Barley, Atmos. Chem. Phys., 2010, 10, 10255-10272.

25 M. Shiraiwa and J. H. Seinfeld, Geophys. Res. Lett., 2012, 39, L24801.

26 V. Perraud, E. A. Bruns, M. J. Ezell, S. N. Johnson, Y. Yu, M. L. Alexander, A. Zelenyuk, D. Imre, W. L. Chang, 
D. Dabdub, J. F. Pankow and B. J. Finlayson-Pitts, Proc. Natl. Acad. Sci. U. S. A., 2012, 109, 2836-2841.

27 J. F. Pankow, Atmos. Environ., 2003, 37, 3323-3333.

28 A. Zuend and J. H. Seinfeld, Fluid Phase Equilib., 2013, 337, 201-213.

29 A. Zuend, C. Marcolli, B. P. Luo and T. Peter, Atmos. Chem. Phys., 2008, 8, 4559-4593.

30 A. Zuend, C. Marcolli, A. M. Booth, D. M. Lienhard, V. Soonsin, U. K. Krieger, D. O. Topping, G. McFiggans, T. Peter and J. H. Seinfeld, Atmos. Chem. Phys., 2011, 11, 9155-9206.

31 M. L. Smith, M. Kuwata and S. T. Martin, Aerosol Sci. Technol., 2011, 45, 244-261.

32 S. P. Hersey, J. S. Craven, A. R. Metcalf, J. Lin, T. Lathem, K. J. Suski, J. F. Cahill, H. T. Duong, A. Sorooshian, H. H. Jonsson, M. Shiraiwa, A. Zuend, A. Nenes, K. A. Prather, R. C. Flagan and J. H. Seinfeld, J. Geophys. Res.: Atmos., 2013, 118, 3016-3036.

33 N. L. Ng, M. R. Canagaratna, Q. Zhang, J. L. Jimenez, J. Tian, I. M. Ulbrich, J. H. Kroll, K. S. Docherty, P. S. Chhabra, R. Bahreini, S. M. Murphy, J. H. Seinfeld, L. Hildebrandt, N. M. Donahue, P. F. DeCarlo, V. A. Lanz, A. S. H. Prevot, E. Dinar, Y. Rudich and D. R. Worsnop, Atmos. Chem. Phys., 2010, 10, 4625-4641.

34 J. Duplissy, P. F. DeCarlo, J. Dommen, M. R. Alfarra, A. Metzger, I. Barmpadimos, A. S. H. Prevot, E. Weingartner, T. Tritscher, M. Gysel, A. C. Aiken, J. L. Jimenez, M. R. Canagaratna, D. R. Worsnop, D. R. Collins, J. Tomlinson and U. Baltensperger, Atmos. Chem. Phys., 2011, 11, 1155-1165.

35 M. Shiraiwa, C. Pfrang, T. Koop and U. Pöschl, Atmos. Chem. Phys., 2012, 12, 2777-2794.

36 L. Renbaum-Wolff, J. W. Grayson, A. P. Bateman, K. Kuwata, M. Sellier, B. J. Murray, J. E. Schilling, S. T. Martin and A. K. Bertram, Proc. Natl. Acad. Sci. U. S. A., 2013, 110, 8014-8019.

37 E. Abramson, D. Imre, J. Beranek, J. M. Wilson and A. Zelenyuk, Phys. Chem. Chem. Phys., 2013, 15, 2983-2991.

38 A. P. Grieshop, N. M. Donahue and A. L. Robinson, Geophys. Res. Lett., 2007, 34, L14810.

39 I. Riipinen, J. R. Pierce, N. M. Donahue and S. N. Pandis, Atmos. Environ., 2010, 44, 597-607.

40 B. Zobrist, V. Soonsin, B. P. Luo, U. K. Krieger, C. Marcolli, T. Peter and T. Koop, Phys. Chem. Chem. Phys., 2011, 13, 3514-3526.

41 S. Takahama and L. M. Russell, J. Geophys. Res.: Atmos., 2011, 116, D02203.

42 T. Raatikainen, R. H. Moore, T. L. Lathem and A. Nenes, Atmos. Chem. Phys., 2012, 12, 4227-4243.

43 D. L. Bones, J. P. Reid, D. M. Lienhard and U. K. Krieger, Proc. Natl. Acad. Sci. U. S. A., 2012, 109, 11613-11618.

44 B. J. Murray, T. W. Wilson, S. Dobbie, Z. Q. Cui, S. Al-Jumur, O. Mohler, M. Schnaiter, R. Wagner, S. Benz, M. Niemand, H. Saathoff, V. Ebert, S. Wagner and B. Karcher, Nat. Geosci., 2010, 3, 233-237.
45 B. B. Wang, A. T. Lambe, P. Massoli, T. B. Onasch, P. Davidovits, D. R. Worsnop and D. A. Knopf, J. Geophys. Res.: Atmos., 2012, 117, D16209.

46 I. J. George and J. P. D. Abbatt, Nat. Chem., 2010, 2, 713-722.

47 M. Shiraiwa, U. Pöschl and D. A. Knopf, Environ. Sci. Technol., 2012, 46, 6630-6636.

48 Y. Katrib, G. Biskos, P. R. Buseck, P. Davidovits, J. T. Jayne, M. Mochida, M. E. Wise, D. R. Worsnop and S. T. Martin, J. Phys. Chem. A, 2005, 109, 10910-10919.

49 E. N. Escoreia, S. J. Sjostedt and J. P. D. Abbatt, J. Phys. Chem. A, 2010, 114, 13113-13121.

50 P. T. Griffiths, C. L. Badger, R. A. Cox, M. Folkers, H. H. Henk and T. F. Mentel, J. Phys. Chem. A, 2009, 113, 5082-5090.

51 L. M. Cosman and A. K. Bertram, J. Phys. Chem. A, 2008, 112, 4625-4635.

52 M. Kuwata and S. T. Martin, Proc. Natl. Acad. Sci. U. S. A., 2012, 109, 17354-17359.

53 A. Zelenyuk, D. Imre, J. Beránek, E. Abramson, J. Wilson and M. Shrivastava, Environ. Sci. Technol., 2012, 46, 12459-12466.

54 J. H. Kroll, N. M. Donahue, J. L. Jimenez, S. H. Kessler, M. R. Canagaratna, K. R. Wilson, K. E. Altieri, L. R. Mazzoleni, A. S. Wozniak, H. Bluhm, E. R. Mysak, J. D. Smith, C. E. Kolb and D. R. Worsnop, Nat. Chem., 2011, 3, 133-139.

55 A. Vlasenko, I. J. George and J. P. D. Abbatt, J. Phys. Chem. A, 2008, 112, 1552-1560.

56 L. H. Renbaum and G. D. Smith, Phys. Chem. Chem. Phys,, 2009, 11, 2441-2451.

57 C. Pfrang, M. Shiraiwa and U. Pöschl, Atmos. Chem. Phys., 2011, 11, 7343-7354.

58 M. E. Jenkin, S. M. Saunders and M. J. Pilling, Atmos. Environ., 1997, 31, 81-104.

59 S. M. Saunders, M. E. Jenkin, R. G. Derwent and M. J. Pilling, Atmos. Chem. Phys., 2003, 3, 161-180.

60 S. Compernolle, K. Ceulemans and J. F. Muller, Atmos. Chem. Phys., 2011, 11, 9431-9450.

61 J. F. Pankow, Atmos. Environ., 1994, 28, 185-188.

62 N. M. Donahue, A. L. Robinson, C. O. Stanier and S. N. Pandis, Environ. Sci. Technol., 2006, 40, 02635-02643.

63 A. Zuend, C. Marcolli, T. Peter and J. H. Seinfeld, Atmos. Chem. Phys., 2010, 10, 7795-7820.

64 A. Apelblat, J. Chem. Thermodyn., 1993, 25, 1513-1520.

65 V. G. Ciobanu, C. Marcolli, U. K. Krieger, A. Zuend and T. Peter, J. Phys. Chem. A, 2010, 114, 9486-9495.

66 A. Bodsworth, B. Zobrist and A. K. Bertram, Phys. Chem. Chem. Phys., 2010, 12, 12259-12266.

67 A. A. Zardini, S. Sjogren, C. Marcolli, U. K. Krieger, M. Gysel, E. Weingartner, U. Baltensperger and T. Peter, Atmos. Chem. Phys., 2008, 8, 5589-5601.

68 U. Pöschl, Y. Rudich and M. Ammann, Atmos. Chem. Phys., 2007, 7, 5989-6023.

69 M. Bilde, B. Svenningsson, J. Monster and T. Rosenorn, Environ. Sci. Technol., 2003, 37, 1371-1378. 
70 R. B. Bird, W. E. Stewart and E. N. Lightfoot, Transport Phenomena, John Wiley \& Sons, Inc, New York, 2nd edn, 2007.

71 M. Shiraiwa, Y. Sosedova, A. Rouviere, H. Yang, Y. Zhang, J. P. D. Abbatt, M. Ammann and U. Pöschl, Nat. Chem., 2011, 3, 291-295.

72 V. K. S. Shante and S. Kirkpatrick, Adv. Phys., 1971, 20, 325-357.

73 T. Murata, M. S. Lee and A. Tanioka, J. Colloid Interface Sci., 1999, 220, 250-254.
74 D. Champion, M. Le Meste and D. Simatos, Trends Food Sci. Technol., 2000, 11, 41-55.

75 R. S. Farr and R. D. Groot, J. Chem. Phys., 2009, 131, 244104.

76 C. Kittel, Introduction to Solid State Physics, Wiley, 1996.

77 J. Fitzpatrick, R. B. Malt and F. Spaepen, Phys. Lett. A, 1974, 47, 207-208.

78 J. E. Shilling, Q. Chen, S. M. King, T. Rosenoern, J. H. Kroll, D. R. Worsnop, P. F. DeCarlo, A. C. Aiken, D. Sueper, J. L. Jimenez and S. T. Martin, Atmos. Chem. Phys., 2009, 9, 771-782. 